\title{
Perspectives on the N-Methyl-D- Aspartate/Nitric Oxide Cascade and Opioid Tolerance
}

Gavril W. Pasternak, M.D., Ph.D., Yuri A. Kolesnikov, M.D., Ph.D., and Anna-Marie Babey, Ph.D.

Opioid tolerance can be modulated by the N-methyl-Daspartate/nitric oxixde (NMDA/NO) cascade. Evidence exploring a daily injection paradigm indicates that agents antagonizing NMDA receptors can prevent tolerance to morphine and delta drugs, but not kappa agents. Drugs work regardless of whether they act as competitive or noncompetitive antagonists. Even an agent acting as an antagonist on the glycine site of the NMDA receptor is effective. Blockade of nitric oxide synthase has similar

KEY WORDS: Opioids; Tolerance; Dependence; Opioid receptor; NMDA; Nitric oxide; Analgesia; Methylene blue; Withdrawal

Opioids modulate the perception of pain through a variety of receptor systems (for review, see Pasternak 1993). The identification and classification of the various opiate receptor subtypes initially rested upon their pharmacologic functions in vivo and in bioassays and then moved to basic studies, including receptor binding and now molecular biology (Uhl et al. 1994). There are four major families of opioid receptors that have been defined in binding and pharmacologic assays: mu, delta, kappa $a_{1}$, and kappas. All the families have been cloned and show a large degree of homology among

From the Laboratory of Neuro-Oncology Memonal Sloan-Kettering Cancer Center, New York, New York

Address correspondence to: Dr. Gavril Wh. Pasternak, Department of Neurology, Memorial Sloan-Kettering Cancer Center, 1275 York Avenue, New York, NY 10021.

Received December 7. 1994; revised April 5 1995, accepted Mar 3, 1995. effects on opioid tolerance, preventing morphine and delta tolerance but not that of kappa drugs. Even methylene blue, which can inhibit guanylyl cyclase activity, is effective, presumably by blocking cGMP formation resulting from $N O$ release. These results demonstrate the importance of an intact NMDA/NO cascade in the production of opioid tolerance and open new possibilities in the design of agents acting on opioid tolerance. [Neuropsychopharmacology 13:309-313, 1995]

themselves. Selective antagonists have been developed that block the actions of the mu, delta, or kappa classes (for review, see Pasternak 1993). Although no selective kappa 3 antagonists yet have been developed, kappa $_{3}$ actions are readily reversed by general opioid antagonists such as Win44,441. Antisense studies also readily distinguish among the four major families (Standifer et al. 1994; Chien et al. 1994; Rossi et al. 1994; Bilsky et al. 1994). Short oligodeoxynucleotides complimentary to regions of the mRNA encoding the various different receptors selectively down-regulate the functions of a single receptor class without interfering with the others. Indeed, the ability of oligodeoxynucleotide antisense studies to down-regulate kappa 3 analgesia without interfering with $\mathrm{mu}$, delta, or kappa 1 provides some of the strongest evidence for a selective kappa 3 receptor system (Pan et al., 1994; Pan et al., 1995).

Tolerance to opioids results from a number of mechanisms that lead to a progressive decrease in the opioid activity at the receptor, cellular, and systems levels (Smith et al. 1988). At the receptor level, there is evi- 


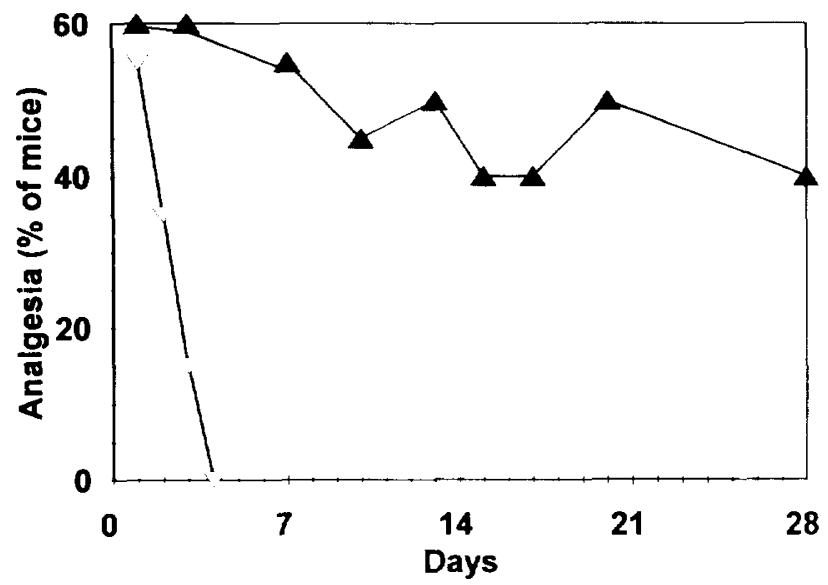

Figure 1. Blockade of morphine tolerance by NOArg. Groups of mice received morphine $(5 \mathrm{mg} / \mathrm{kg}, \mathrm{SC})$ alone $(-7-)$ or with NOArg ( $2 \mathrm{mg} / \mathrm{kg} /$ day $)(-\boldsymbol{\Delta}-)$. Results are from Kolesnikov et al. (1993a).

dence for desensitization and down-regulation, possibly due to phosphorylation of the receptors. At the same time, cellular changes have been associated with tolerance. Early studies demonstrated that chronic exposure to opioids up-regulates adenylate cyclase levels, partially overcoming the inhibitory effects of the opiates on this system. Finally, tolerance may be manifested through the up-regulation of antagonistic systems and/or the concurrent down-regulation of facilitative ones. The mechanisms of tolerance are almost certainly complex and comprise a variety of all three components. Equally important, tolerance develops to each of the opioid receptor families independently, enabling the use of cross-tolerance to define the receptor mechanisms of various drugs. In the current studies, we have focused upon the role of antagonistic nonopioid systems in the production of opioid tolerance.

\section{NMDA RECEPTORS}

After the initial observations that MK-801, a noncompetitive N-methyl-D-aspartate (NMDA) antagonist, prevents morphine tolerance, similar effects have been observed with competitive NMDA antagonists (Truijillo and Akil 1991; Ben-Eliyahuy et al. 1992; Marek et al. 1991; Tiseo and Inturrisi 1993; Elliot et al. 1994). These studies have now been extended to the competitive NMDA antagonist LY274614, which also protects against morphine tolerance (Tiseo and Inturrisi 1993; Tiseo et al. 1994; Elliot et al. 1994). However, this action is selective. Like the nitric oxide synthase (NOS) inhibitors (Kolesnikov et al. 1992, 1993a), MK-801 and LY274614 are inactive against kappa $a_{1}(\mathrm{U} 50,488 \mathrm{H}$ ) or kappa 3 (naloxone benzoylhydrazone or $\mathrm{NalBzoH}$ ) tolerance (Elliot et al. 1994). This ability to dissociate the mechanisms
Table 1. Effect of NOArg and Arginine on Morphine Analgesia

\begin{tabular}{lcc}
\hline & \multicolumn{2}{c}{ Morphine ED $\mathbf{5 0}(\mathbf{m g} / \mathbf{k g})$} \\
\cline { 2 - 3 } Treatment & Without NOArg & With NOArg \\
\hline Morphine & & \\
Acute & $4.4(3.6,5.3)$ & $3.9(2.8,5.4)$ \\
5 days & $8.8(6.2,11.3)$ & $4.6(3.1,6.7)$ \\
10 days & $17.2(11.8,23.8)$ & $5.8(4.0,8.7)$ \\
28 days & $37.8(26.6,51.1)$ & - \\
L-arginine & & - \\
Acute & $6.6(4.8,8.5)$ & - \\
3 days & $9.9(7.5,12.5)$ & - \\
5 days & $10(7.0,13.6)$ & - \\
10 ays & $8.7(6.1,12.2)$ & - \\
D-arginine & & \\
Acute & $4.6(2.7,5.9)$ & - \\
5 days & $4.4(2.4,6.1)$ & $5.7)$ \\
\hline
\end{tabular}

Morphine $\mathrm{ED}_{50}$ values with $95 \%$ confidence limits were determined in mice receiving only the designated treatment alone or coupled with daily injections of NOArg $(2 \mathrm{mg} / \mathrm{kg})$. Acute studies examined the actions of the agents $30 \mathrm{~min}$ after injection. Chronic dosing was done with once daily injections of morphine $(5 \mathrm{mg} / \mathrm{kg})$ alone or in combination with NOArg $(2 \mathrm{mg} / \mathrm{kg})$, L-arginine $(600$ $\mathrm{mg} / \mathrm{kg}$, i.p. ) alone or in combination with NOArg $(2 \mathrm{mg} / \mathrm{kg})$ or only D-arginine $(600 \mathrm{mg} / \mathrm{kg})$ for the stated number of days. The ED50 values are from the literature (Kolesnikov et al. 1993; Babey et al. 1994)

of tolerance produced by mu and kappa systems raises important issues in the understanding of the two different types of systems.

Another competitive NMDA antagonist, NPC17742, also prevents tolerance when co-administered with morphine (Kolesnikov et al. 1993b). However, its profile against the other opioid receptor subtypes is unique. Unlike MK-801, LY274614, or the NOS inhibitors, NPC17742 also prevents tolerance to the kappa $a_{1}$ analgesic $\mathrm{U} 50,488 \mathrm{H}$. Its inability to prevent tolerance associated with $\mathrm{NalBzoH}$ provides further evidence for distinct mechanisms of kappa $a_{1}$ and kappa $a_{3}$ tolerances.

1-Aminocyclopropyl carboxylic acid (ACPC) acts as antagonist at the glycine site on the NMDA receptor. Like the other agents acting at the NMDA receptor, ACPC prevents tolerance to morphine but is inactive against kappa ${ }_{1}$ and kappa 3 tolerance (Kolesnikov et al., 1994). Like the others, ACPC also reverses preestablished tolerance.

\section{NITRIC OXIDE SYNTHASE INHIBITORS}

\section{Morphine}

In view of the strong correlation between activation of NMDA receptors and the subsequent production of nitric oxide (NO), we studied the actions of the nitric oxide synthase (NOS) inhibitor $\mathrm{N}^{\mathrm{C}}$-nitro-L-arginine 


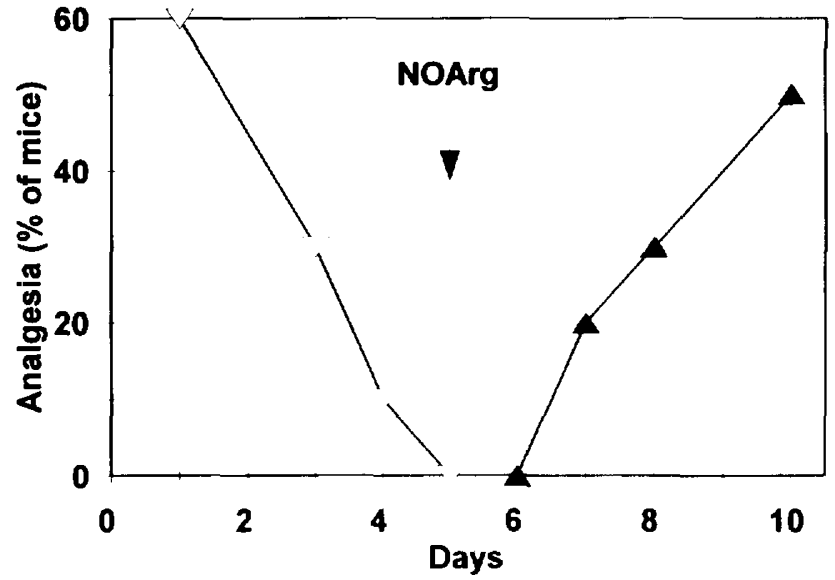

Figure 2. Reversal of morphine tolerance by NOArg. Mice received morphine alone ( $5 \mathrm{mg} / \mathrm{kg}, \mathrm{SC}$ ) for 5 days $(-7-)$. Starting on day 6 , the mice received daily doses of morphine in conjunction with NOArg through day $10(-\mathbf{A}-)$. Results are from Kolesnikov et al. (1993a)

(NOArg; Kolesnikov et al., 1992, 1993a; Babey et al., 1994). NOArg potently blocks morphine tolerance in the traditional morphine pellet paradigm as well as with a daily opioid injection paradigm. Indeed, coadministration of morphine with NOArg led to analgesia for at least 28 days, the longest time tested, whereas complete tolerance developed to morphine alone within 5 days (Figure 1). Like the NMDA drugs, the actions of NOArg are limited to tolerance. Given acutely with morphine, NOArg has no effect upon morphine analgesia (Table 1).

NOArg also reverses preestablished morphine tolerance (Figure 2; Klesnikov et al. 1993a). Animals tolerant to morphine regained their analgesic sensitivity over 5 days when NOArg was given along with the daily morphine injections. The return of morphine sensitivity in the animals receiving both morphine and NOArg is more rapid than another group made abstinent over the same time period (Kolesnikov et al. 1993a).

The ability to block morphine tolerance is not limited to NOArg. Similar results are seen with another NO synthase inhibitor, NAME, although it is not quite as effective and its actions not as long-lasting (Babey et al. 1994).

NO is a readily diffusible gas, making its storage impractical (Bredt and Snyder 1992). Thus, it is generated from arginine by NOS as needed. We next examined possible mechanisms associated with $\mathrm{NO}$ and morphine tolerance. Morphine administration does not change the levels of NOS in the brain nor does it change NOS mRNA levels, measured with a solution hybridization assay (Babey et al. 1994). Thus, the NO involved with morphine tolerance is generated from preexisting enzyme without the need to induce more.

$\mathrm{L}$-arginine is the substrate for NOS, leading to the production of NO. Driving the enzyme to generate NO by administering L-arginine along with morphine accelerates tolerance. D-arginine, the inactive isomer, has no effect. Interestingly, L-arginine given alone lowers morphine's analgesic response after a single dose (Table 1). Repeated dosing with L-arginine alone shifts morphine's analgesic dose-response curves to the right with a timecourse similar to that associated with morphine tolerance. However, unlike morphine, whose continued administration over 28 days leads to a progressive increase in tolerance, the shift due to L-arginine plateaus between 2- and 3-fold after only 4 to 5 days. In a sense, L-arginine makes naive animals "tolerant."

The actions of NOArg are limited to tolerance. Administered acutely with morphine, NOArg has no effect on morphine's analgesic potency. Equally important, NOArg is inactive as an analgesic when given alone. Even continued administration of NOArg for 10 days alone does not influence morphine's analgesic efficacy. Thus, the actions of NOArg appear to be related directly on the mechanisms of tolerance and are not simply a potentiation of morphine's analgesic effectiveness.

NO activates guanylyl cyclase, as well as a number of other actions. Methylene blue inhibits guanylyl cyclase, although the selectivity of its actions remains a matter of controversy. Methylene blue, however, effectively blocks morphine tolerance in our model, consistent with a cascade going from the activation of NMDA receptors, production of $\mathrm{NO}$, and possibly activation of guanylyl cyclase.

Classic studies with morphine have established a close relationship between tolerance and dependence. Current work with both the NMDA antagonists and NOS inhibitors confirm this association. Paradigms which interfere with morphine tolerance have similar effects on morphine dependence (Kimes et al. 1993; Kolesnikov et al. 1993a; Adams et al. 1993). Coadministration of the NMDA antagonists or NOArg along with morphine prevents the development of tolerance. Equally important, they can reverse preestablished tolerance even with the continued administration of morphine.

\section{Delta and Kappa Tolerance}

As noted before, NMDA antagonists and NOArg effectively reverse the tolerance induced by morphine. Additional studies have indicated a similar effect on tolerance induced by repeated administration of DPDPE intrathecally. However, kappa tolerance is different. The traditional NMDA antagonists such as MK-801 and LY274614, as well as NOArg, have no effect on tolerance to the kappa $a_{1}$ agent $U 50,488 \mathrm{H}$ or the kappa 3 , drug NalBzoH in mice. There is one exception: NPC17742, a putative competitive NMDA antagonist. Like the others, NPC17742 blocks morphine and DPDPE toler- 
ance. However, it also is effective against U50, $488 \mathrm{H}$, but not NalBzoH tolerance. The reasons behind the difference in selectivity for NPC17742 and the other NMDA antagonists is not clear. However, NPC17742 does provide evidence for distinct kappa ${ }_{1}$ and kappa 3 mechanisms of tolerance.

\section{SUMMARY}

The ability to selectively modulate opioid tolerance and dependence without interfering with analgesia is an important observation. Clinically, it opens many new potential treatment approaches. It also provides many insights into the mechanisms mediating these actions. First, it provides proof for the presence of separate and distinct mechanisms for analgesia compared to tolerance/dependence. It also provides additional evidence supporting the close association between tolerance and dependence. A second major point is the separation of the mu and delta tolerance from the two kappa systems. Virtually all the drugs acting on this cascade system dissociate kappa tolerance from $\mathrm{mu}$ and delta tolerance. The one exception, NPC17746, further differentiates kappa $a_{3}$ from kappa3 systems.

In conclusion, studies from our group and others confirm the role of NMDA and NO synthase in opiate tolerance. However, tolerance involves many mechanisms (Smith et al. 1988). Desensitization, downregulation, and cellular changes in signal transduction systems all have been implicated. The mechanisms responsible for tolerance may depend upon the drugs used, their dose, route of administration and frequency, as well as the duration of treatment. Thus, tolerance and dependence remain complex effects, which only have been partially elucidated. Furthermore, it is clear that the final step responsible for tolerance and dependence is neither the activation of the NMDA receptor nor the activation of NO synthase. Blockade of either will reverse preestablished tolerance and dependence, but slowly over several days. If they were the last step, an immediate reversal would have been anticipated. Early studies have suggested that tolerance is dependent upon protein synthesis. The slow reversal of tolerance and dependence might correspond to the turnover of a protein induced by the administration of the opiate. Identification of this putative protein would be important in the further understanding of the tolerance cascade.

\section{ACKNOWLEDGMENTS}

We would like to thank Drs. Posner and Rapaka for their assistance with these studies. This work was supported in part by a grant (DA07242) and a Research Scientist Award
(DA00220) from the National Institute on Drug Abuse to GWP (DA07242) and a core grant from the National Cancer Institute to Memorial Sloan-Kettering Cancer Center (CA08748). YAK is supported in part by the Norman and Rosita Winston Foundation and the Michael and Ethyl Cohen Fellowship Fund.

\section{REFERENCES}

Adams ML, Kalicki JM, Meyer ER, Cicero TJ (1993): Inhibition of the morphine withdrawal syndrome by a nitric oxide synthase inhibitor, $\mathrm{NG}^{\mathrm{G}}$-nitro-L-arginine methyl ester. Life Sci 52:245-249

Babey AM, Kolesnikov Y, Cheng J, Inturrisi CE, Trifilletti RR, Pasternak GW (1994): Nitric oxide and opioid tolerance. Neuropharmacology 33:1463-1470

Ben-Eliyahu S, Marek P, Vaccarino AL, Mogil JS, Sternberg WF, Liebeskind JC (1992): The NMDA receptor antagonist MK-801 prevents long-lasting nonassociative morphine tolerance in the rat. Brain Res 575:304-308

Bilsky EF, Bernstein N, Pasternak GW, Hruby VJ, Patel D, Porreca F, Lai J (1994): Selective inhibition of [D-Ala2, $\mathrm{Glu}^{4}$ ]deltorphin antinociception by supraspinal, but not spinal, administration of an antisense oligodeoxyunucleotide to an opioid delta receptor. Life Sci 57:PL79-84

Bredt DS, Snyder SH (1992): Nitric oxide, a novel neuronal messenger. Neuron 8:3-11

Chien CC, Brown G, Pan YX, Pasternak GW (1994): Blockade of $\mathrm{U} 50,488 \mathrm{H}$ analgesia by antisense oligodeoxynucleotides to a kappa opioid receptor. Eur J Pharmacol 253:R7-8

Elliot K, Minami N, Kolesnikov Y, Pasternak GW, Inturrisi CE (1994): The NMDA receptor antagonists, LY274614 and $\mathrm{MK}-801$, and the nitric oxide synthase inhibitor, $\mathrm{NG}^{\mathrm{G}}$ nitro- $\mathrm{L}$-arginine, attenuate analgesic tolerance to the $\mathrm{mu}$ opioid morphine but not to kappa opioids. Pain 56:69-75

Kimes AS, Vaupel DB, London ED (1993): Attenuation of some signs of opioid withdrawal by inhibitors of nitric oxide synthase. Psychopharmacology (Berl) 112:521-524

Kolesnikov YA, Ferkany J, Pasternak GW (1993): Blockade of mu and kappa 1 opioid analgesic tolerance by NPC17742, a novel NMDA antagonist. Life Sci 53:1489-1494

Kolesnikov Y, Maccechini ML, Pasternak GW (1994): 1-Aminocyclopropane carboxylic acid (ACPC) prevents mu and delta opioid tolerance. Life Sci 55:1393-1398

Kolesnikov YA, Pick CG, Pasternak GW (1992): NG-Nitro-Larginine prevents morphine tolerance. Eur J Pharmacol 221:399-400

Kolesnikov YA, Pick CG, Ciszewska G, Pasternak GW (1993): Blockade of tolerance to morphine but not to $\kappa$ opioids by a nitric oxide synthase inhibitor. Proc Natl Acad Sci USA 90:5162-5166

Marek P, Ben-Eliyahu S, Vaccarino AL, Liebeskind JC (1991): Delayed application of MK-801 attenuates development of morphine tolerance in rats. Brain Res 558:163-165.

Pan YX, Cheng J, Xi J, Brooks AI, Standifer KM, Pasternak GW (1994): Cloning and expression of a kappaz-related opioid receptor. Regul Pep 54:217-218

Pan YX, Cheng J, Xu J, Rossi G, Jacobson E, Ryan-Moro J, Brooks AI, Dean GE, Standifer KM, Pasternak GW (1995): 
Cloning and functional characterization of a kappa 3 related opioid receptor. Mol Pharmacol 47:1180-1188

Pasternak G (1993): Phamacologic mechanisms of opioid analgesics. Clin Neuropharmacol 16:1-18

Rossi G, Pan YX, Cheng J, Pasternak GW (1994): Blockade of morphine analgesia by an antisense oligodeoxynucleotide against the mu receptor. Life Sci 54:PL375-379

Smith AP, Law PY, Loh HH (1988): Role of opioid receptors in narcotic tolerance/dependence. In Pasternak GW (ed), The Opiate Receptors. Clifton, NJ, Humana, pp 441-488

Standifer KM, Chien CC, Wahlestedt C, Brown GP, Pasternak GW (1994): Selective loss of delta opioid analgesia and binding by antisense oligodeoxynucleotides to a delta opioid receptor. Neuron 12:805-810

Thorat SN, Reddy PL, Bhargava HN (1993): Evidence for the role of nitric oxide in kappa-opiate tolerance in mice. Brain Res 621:171-174

Tiseo PJ, Cheng J, Pasternak GW, Inturrisi CE (1994): Modulation of morphine tolerance by the competitive NMDA receptor antagonist LY274614: Assessment of opioid receptor changes. J Pharmacol Exp Ther 268:195-201

Tiseo P, Inturrisi CE (1993): Attenuation and reversal of morphine tolerance by the competitive N-methyl-D-aspartate receptor antagonist, LY274614. J Pharmacol Exp Ther 264:1090-1096

Trujillo KA, Akil H (1991): Inhibition of morphine tolerance and dependence by the NMDA receptor antagonist MK801. Science 251:85-87

Uhl GR, Childers SR, Pasternak GW (1994): An opiate receptor gene family reunion. Trends Neurosci 17:89-93 